\title{
The Proper Ki-67 Cut-Off in Hormone Responsive Breast Cancer: A Monoinstitutional Analysis with Long-Term Follow-Up
}

This article was published in the following Dove Press journal: Breast Cancer: Targets and Therapy

\author{
Augusto Lombardi (iD \\ Rachele Lazzeroni \\ Laura Bersigotti (D) \\ Valeria Vitale \\ Claudio Amanti
}

Department of Breast Surgery, Università di Roma La Sapienza -

OspedaleSant'Andrea, Rome, Italy
Correspondence: Laura Bersigotti OspedaleSant'Andrea, via di Grottarossa 1035, Rome, 00189, Italy

Tel +393332559243

$\mathrm{Fax}+390633775649$

Email laufeberj@hotmail.it
Introduction: Breast cancer is a heterogeneous disease. Our study focuses on a monoinstitutional series of patients affected by Hormone Responsive carcinomas (luminal A and luminal B) and aims to define an optimal Ki-67 cut-off, to correctly stratify these patients into risk classes, using the ImmunoHistoChemical (IHC) surrogates of the Molecular Subtypes, according to the St. Gallen guidelines.

Methods: We analyzed 1685 patients. These patients underwent both radical and conservative surgeries with Sentinel Lymph Node Biopsy eventually followed by Axillary Dissection (AD). Furthermore, all the patients underwent adjuvant therapies according to the guidelines. A retrospective univariate analysis was performed and survival curves (Disease-Related Survival, DRS, and Disease-Free Survival, DFS) were carried out according to the following ki-67 risk classes: Low Risk (Ki-67 $\leq 14 \%$ ); Intermediate Risk (Ki-67 15\% $\div 20 \%$ ); High Risk (Ki-67 > 20\%).

Results: 14 yy DRS was $98 \%$ in LA and $85 \%$ in LB with a ki-67 cut-off of $14 \%$ ( $p=0.037$ ) vs $95 \%$ (LA) and $83 \%$ (LB) with a ki-67 cut-off of $20 \%$ ( $\mathrm{p}=0.003$ ). 14y DFS was $85 \%$ in LA and $72 \%$ in LB with a ki-67 cut-off of $14 \%$ ( $\mathrm{p}=0.017)$ vs $83 \%$ (LA) and $66 \%$ (LB) with a ki-67 cut-off of $20 \%(\mathrm{p}<0.000)$.

Discussion: Our results confirmed that the $20 \% \mathrm{Ki}-67$ cut-off is more reliable in differentiating patients at low or high risk of recurrence and death, and stratifying patients eligible for adjuvant chemotherapy. Thus, despite its poor reproducibility, the identification of the most accurate ki-67 index assumes a pivotal relevance in guiding a tailored strategy among patients with this specific profile of breast cancer, as well as the molecular surrogates, in order to avoid harmful overtreatments.

Keywords: Ki67, molecular subtypes, immunohistochemistry

\section{Introduction}

Breast cancer is a heterogeneous disease. An important step forward in the field of breast cancer classification is related to the characterization of molecular subtypes.

About 20 years ago, Perou ${ }^{1}$ highlighted how each tumor has an extremely precise genetic signature, that influences the neoplastic behavior in terms of growth, aggression, tendency to metastasize, and consequently the prognosis.

Waiting for multigene panels entering in routine clinical practice, the immunohistochemical (IHC) surrogates of the molecular subtypes of breast cancer proposed by the Saint Gallen Consensus Meetings have been widely used to classify and stratify patients into various risk categories. ${ }^{2}$ 
The main difficulty concerns with the differentiation of the luminal forms, A and B. In fact, both tumors are estrogen receptor positive $(\mathrm{OR}+)$ and HER2 negative. With this aim, the guidelines proposed by the Saint Gallen Consensus Meetings recommend the evaluation of the $\mathrm{Ki}-67$ proliferation index, a nuclear protein, detectable with IHC, that is a marker indicative of cell expansion, which is expressed in all phases of the cell cycle, except G0. ${ }^{3}$ The Luminal B subtype should exhibit a higher Ki-67 proliferation index than the Luminal A type; however, the Ki-67 cut-off for the differentiation of these two categories has changed over time. In fact, in 2011 the Saint Gallen Consensus Meeting defined as "low proliferation" breast tumors those with an index of Ki- $67<14 \%$, a cut-off based on the median value of its distribution. However, during the 2013 Saint Gallen Consensus Meeting, most experts stated that a threshold of $\geq 20 \%$ was indicative of a higher risk class. At the same time, several studies have shown a low reproducibility of the Ki-67 marker, mainly in a subgroup of breast tumors with intermediate proliferation activity, such as between 15 and $30 \%$.

Thus, the aim of this paper is to establish which is the optimal Ki-67 cut-off (14 vs $20 \%$ ) to stratify and define the proper IHC surrogate of breast cancer molecular subtypes with the ultimate purpose of customizing the therapy for patients as much as possible, in order to avoid harmful overtreatments. ${ }^{7-11}$

\section{Materials and Methods}

This retrospective work is based on a prospective database of 2250 patients affected by primary breast cancer collected from October 2004 to September 2020. They all underwent surgical procedures at the Breast Surgery Unit of the Sant'Andrea Hospital, of Rome. Exclusion criteria include: diagnosis of Carcinoma in situ, neoadjuvant

Table I Clinical-Pathological Characteristics of the Study Population

\begin{tabular}{|c|c|c|c|c|c|c|c|}
\hline & Total & $K i 67<14 \%$ & $K i 67 \geq 14 \%$ & $p$ & Ki67<20\% & $K i 67 \geq 20 \%$ & $\mathbf{P *}$ \\
\hline \multicolumn{8}{|l|}{ Age } \\
\hline$<5$ I & 537 (32\%) & $250(30 \%)$ & $287(34 \%)$ & 0.13 & $373(31 \%)$ & $164(33 \%)$ & 0.10 \\
\hline$>50$ & II 48 (68\%) & 594 (70\%) & $554(66 \%)$ & & $813(69 \%)$ & $338(67 \%)$ & \\
\hline \multicolumn{8}{|l|}{ Axillary state } \\
\hline No & $1248(74 \%)$ & $680(81 \%)$ & $568(67 \%)$ & $<0.0001$ & $918(77 \%)$ & $330(66 \%)$ & $<0.0001$ \\
\hline $\mathrm{N}+$ & $436(26 \%)$ & $162(19 \%)$ & $274(33 \%)$ & & $266(23 \%)$ & $170(34 \%)$ & \\
\hline $\mathrm{Nx}$ & $\mathrm{I}(=\mid \%)$ & & $\mathrm{I}(0.1 \%)$ & & & & \\
\hline T size (average, $\mathrm{mm}$ ) (missing 2 ) & $15.2( \pm 9.6)$ & $13.3( \pm 9.0)$ & $17.0( \pm 9.9)$ & $<0.0001$ & $13.9( \pm 9.0)$ & $18.2( \pm 10.4)$ & $<0.0001$ \\
\hline \multicolumn{8}{|l|}{ Grading } \\
\hline GI & $593(35 \%)$ & 477 (80\%) & $116(20 \%)$ & $<0.0001$ & 577 (97\%) & $16(3 \%)$ & $<0.0001$ \\
\hline $\mathrm{G} 2$ & 739 (44\%) & 347 (47\%) & $392(53 \%)$ & & $554(75 \%)$ & $185(25 \%)$ & \\
\hline G3 & $346(20 \%)$ & $18(5 \%)$ & $328(95 \%)$ & & $48(14 \%)$ & $298(86 \%)$ & \\
\hline Not evaluated & $7(0.4 \%)$ & 0 & 7 (100\%) & & $5(71 \%)$ & $2(29 \%)$ & \\
\hline \multicolumn{8}{|l|}{ Lymphovascular invasion } \\
\hline LO & 1505 (89\%) & $784(93 \%)$ & 721 (85\%) & $<0.0001$ & $1084(92 \%)$ & 421 (84\%) & $<0.0001$ \\
\hline LI & 180 (II\%) & $58(7 \%)$ & $122(15 \%)$ & & $100(8 \%)$ & $80(16 \%)$ & \\
\hline \multicolumn{8}{|l|}{ Histology } \\
\hline Ductal & $1383(82 \%)$ & $660(78 \%)$ & $723(86 \%)$ & $<0.0001$ & 959 (8I\%) & $424(85 \%)$ & 0.012 \\
\hline Lobular & $23 \mid(14 \%)$ & $153(18 \%)$ & $78(9 \%)$ & & $181(15 \%)$ & $50(10 \%)$ & \\
\hline Mixed & $49(3 \%)$ & $20(2 \%)$ & $29(3 \%)$ & & $32(3 \%)$ & 17 (3\%) & \\
\hline Other & $22(1 \%)$ & $9(1 \%)$ & $13(1 \%)$ & & $12(1 \%)$ & $10(2 \%)$ & \\
\hline \multicolumn{8}{|l|}{ Multifocality } \\
\hline False & $1425(85 \%)$ & 713 (85\%) & $712(84 \%)$ & 0.9 & $1004(85 \%)$ & 421 (84\%) & 0.7 \\
\hline True & $260(15 \%)$ & $129(15 \%)$ & 131 (16\%) & & $180(15 \%)$ & $80(16 \%)$ & \\
\hline \multicolumn{8}{|l|}{ Surgery (missing I) } \\
\hline Mastectomy & $244(14 \%)$ & 120 (I4\%) & $124(15 \%)$ & 0.6 & 170 (I4\%) & 74 (I5\%) & 0.3 \\
\hline Quadrantectomy & 1440 (86\%) & 722 (86\%) & 718 (85\%) & & $1014(86 \%)$ & $426(85 \%)$ & \\
\hline
\end{tabular}

Note: $* \chi^{2}$ test or $\mathrm{t}$ Student in case of average values. 
chemotherapy and tumors that do not express estrogen receptors or HER2-enriched.

Therefore, the analysis was conducted among 1685 patients, who underwent both radical and conservative surgery with Sentinel Lymph Node Biopsy and subsequent completion lymph node axillary dissection (AD), when positive. This approach was maintained regardless of the size of the metastasis until 2012 when AD was carried out only in the case of macrometastasis $(>2 \mathrm{~mm})$. On the other side, no $\mathrm{AD}$ was performed in the case of isolated tumor cells (ITC) on Sentinel Lymph Node.

All the patients underwent adjuvant therapies (Radiation Therapy, Hormone therapy and/or Chemotherapy) according to the guidelines. The instrumental and clinical follow-up was conducted in collaboration with the Radiation Therapy and Oncologic Units of our hospital.

The mean age of the sample was 59 years $( \pm 12.7$, range 26-89). The main clinical-pathological characteristics of the sample are reported in the following table (Table 1).

\section{Statistic Analysis and Software}

The prospective database was built by Microsoft ${ }^{\circledR}$ Access. The statistical analysis was carried out by IBM-SPSS ${ }^{\circledR}$. In order to compare categorical and continuous variables, Chi-square test and Student's $t$ test were used. DiseaseRelated Survival (DRS) and Disease-Free Survival (DFS) were calculated from the surgical procedure, plotting the curves by the Kaplan-Meier method and the Log-rank test was used for statistical comparisons.

\section{Results}

Tumor size, Grading, Lympho-Vascular Invasion and Histological type are highly correlated to the Ki-67 proliferative index, while other variables do not show statistically significant correlation (Table 1).

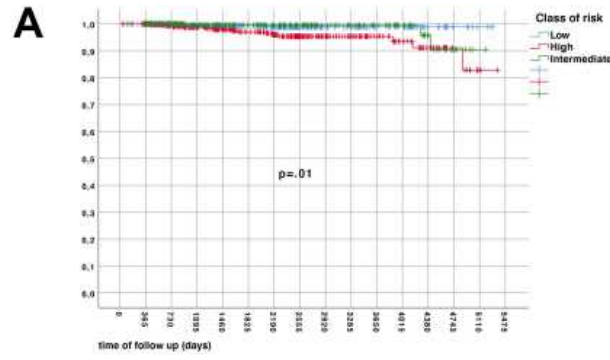

Figure I (A) Disease-related survival and (B) disease-free survival by class of risk.
Table 2 Adverse Events Recorded During the Follow-Up

\begin{tabular}{|l|r|}
\hline Event & \# \\
\hline Local relapses & 37 \\
Axillary relapses & 7 \\
Distant metastasis & 37 \\
Contralateral metachronous tumors & 16 \\
\hline
\end{tabular}

DRS and DFS on the whole sample were, respectively, $98 \%$ and $94 \%$ at 5 years, $97 \%$ and $79 \%$ at 10 years, $88 \%$ and $77 \%$ at 14 years.

Out of 1114 patients who responded to follow-up, 47 deaths were recorded over a period of 14 years (20 directly due to breast cancer, and 27 related to other causes). The adverse events recorded are shown in the following table (Table 2).

We stratified our population according to the Ki-67 value, establishing three categories: Low Risk (Ki-67 $\leq$ 14\%); Intermediate Risk (Ki-67 15\% $\div 20 \%$ ); High Risk (Ki-67 > 20\%). The DRS and DFS curves vary according to the risk class (Figure 1), and the risk of death or relapse seems related to the value of Ki-67 ( $p=0.01$ and $p=0.002$, respectively).

Then, we evaluated the prognostic correlation of the IHC surrogate molecular subtype (Luminal A vs Luminal B), depending on the cut-off set (Ki-67 14\% vs Ki-67 20\%) (Table 3, Figure 2).

Furthermore, a more accurate stratification by risk class, using a $20 \%$ cut-off, could be obtained from the analysis on the subpopulation of patients with at least one positive lymph node. In this set, the difference between the DRS and DFS curves with a ki-67 cut-off of $14 \%$ showed a not significant $p$ value compared with those stratified by a Ki-67 cut-off of $20 \%$ that showed $p=0.006$; and $p=$ 0.003 , respectively. Such a specific analysis of a subset is essentially focused to verify the prognostic impact of the biomarker in patients with an associated risk factor. This

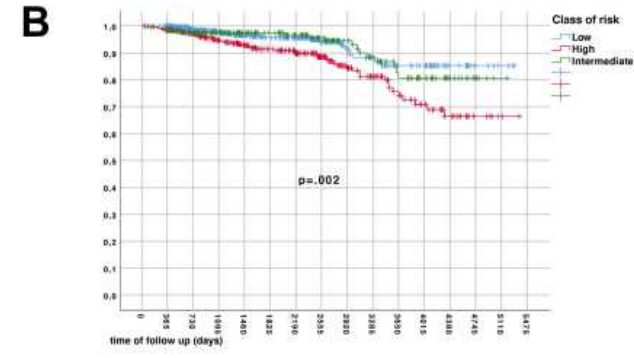


Table 3 Disease-Related Survival (DRS) and Disease-Free Survival (DFS) at 5, 10 and 14 Years by Molecular Subtype (IHC Surrogate) According to Ki67 Cut-Off (I4\% vs 20\%)

\begin{tabular}{|l|l|l|l|l|}
\hline Ki 67 Cut-Off I4\% & $\mathbf{5 y y}$ & I0yy & I4yy & P value* \\
\hline $\begin{array}{l}\text { DRS } \\
\text { Luminal A } \\
\text { Luminal B }\end{array}$ & $99 \%$ & $98 \%$ & $98 \%$ & \\
\hline $\begin{array}{l}\text { DFS } \\
\text { Luminal A } \\
\text { Luminal B }\end{array}$ & $98 \%$ & $97 \%$ & $85 \%$ & $\mathrm{P}=0.037$ \\
\hline $\begin{array}{l}\text { Ki67 cut-off 20\% } \\
\text { DRS } \\
\text { Luminal A } \\
\text { Luminal B }\end{array}$ & $94 \%$ & $85 \%$ & $85 \%$ & \\
\hline $\begin{array}{l}\text { DFS } \\
\text { Luminal A } \\
\text { Luminal B }\end{array}$ & $99 \%$ & $95 \%$ & $95 \%$ & $\mathrm{P}=0.017$ \\
\hline
\end{tabular}

Note: $* \chi^{2}$ test.

results agree with the last revision of the AJCC Staging System, ${ }^{12}$ where an information of a purely staging type (in this case the $\mathrm{N}$ status) is combined with a biological

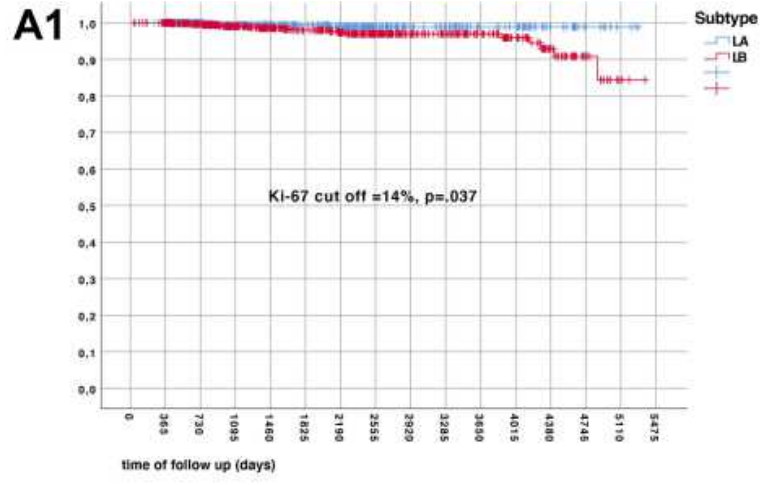

B1

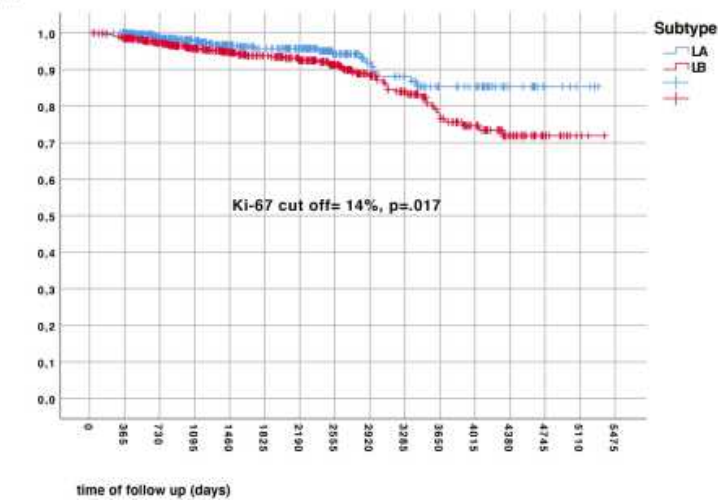

information (the IHC surrogate of the molecular subtype) to assess a proper therapy and predict a correct prognosis.

\section{Discussion and Conclusions}

We can confirm that luminal breast cancer is a pathology with a good prognosis. Further analysis is needed especially focusing on long-term mortality, most of all in luminal B patients.

Despite the usefulness of Ki-67 on the management of breast cancer has been strongly discussed, due to its poor reproducibility, the Saint Gallen Consensus Meeting had suggested, since 2009, to use it for stratifying luminal tumors. Our experimental results confirm that within luminal breast tumors' setting the $20 \% \mathrm{Ki}-67$ cut-off is more reliable in differentiating patients at low or high risk of recurrence and death, identifying patients at higher risk, eligible for adjuvant chemotherapy. This cut-off allows a more correct management of the disease, avoiding an unwarranted overtreatment.

Undoubtedly, we could say that it is time to ascend the phenotypic slope reaching the genotypic top.

The recent results of clinical trials, such as the TAILORx, ${ }^{13}$ show the actual usefulness of the multigenic

A2

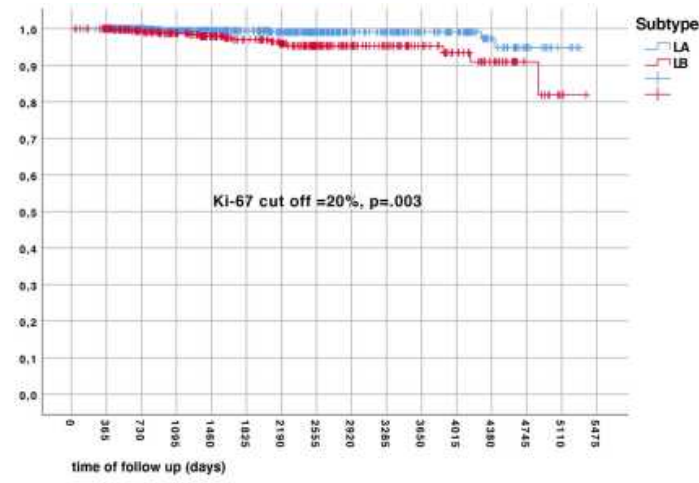

B2

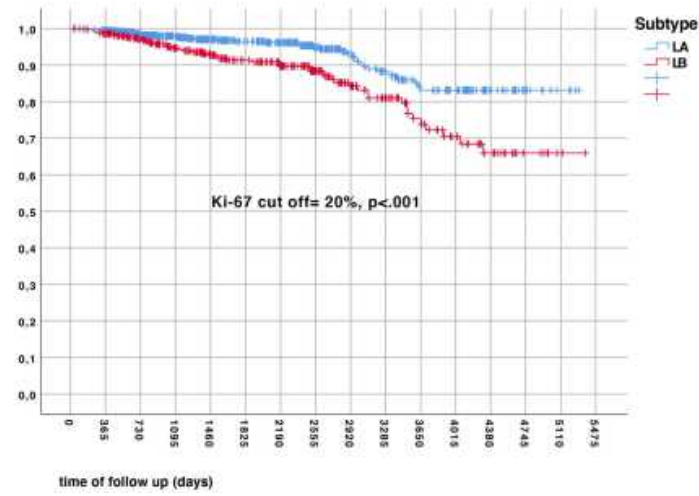

Figure 2 (AI) Disease-related survival with Ki-67 cut-off = 14\%; (A2) disease-related survival with Ki-67 cut-off = 20\%; (B I) disease-free survival with Ki-67 cut-off = I4\%; (B2) disease-free survival with $\mathrm{Ki}-67$ cut-off $=20 \%$.

Abbreviations: LA, luminal A; LB, luminal B. 
panels to assign the most appropriate and effective treatment for these luminal breast cancer patients.

These findings provide significant support to identify a subset of low-risk women who can avoid postsurgical chemotherapy. Just while we are writing, about this issue, the Italian Ministro della Salute (the Public Health Authority) has set up a 20.000.000 € yearly fund to implement into the National Health System the clinical use of the multigene panels in hormone responsive breast cancer patients.

\section{Ethics and Consent Statement}

The authors declare that this is a retrospective study and it does not require approval by the Ethics Committee, but rather, only required approval by the Breast Unit Core Team Institutional Review Board (Professor Claudio Amanti, breast surgery, Professor Mattia Falchetto Osti, radiation oncology, and Professor Patrizia Pellegrini, oncology). Professor Amanti, as an author of the paper, recused himself from the review and approval process undertaken by the institutional review board.

Patient consent to review their medical records was not required by the board because all patients included in the study signed, at admission, a standard form about privacy and processing of personal data.

\section{Disclosure}

The authors report no conflicts of interest in this work.

\section{References}

1. Perou CM, Sørlie T, Eisen MB, et al. Molecular portraits of human breast tumours. Nature. 2000;406(6797):747-752. PMID: 10963602. doi:10.1038/35021093

2. Mittendorf EA, Chavez-MacGregor M, Vila J, et al. Bioscore: a staging system for breast cancer patients that reflects the prognostic significance of underlying tumor biology. Ann Surg Oncol. 2017;24 (12):3502-3509. PMID: 28726077. doi:10.1245/s10434-017-6009-х
3. Bustreo S, Osella-Abate S, Cassoni P, et al. Optimal Ki-67 cut-off for luminal breast cancer prognostic evaluation: a large case series study with a long-term follow-up. Breast Cancer Res Treat. 2016;157 (2):363-371. doi:10.1007/s10549-016-3817-9

4. Goldhirsch A, Wood WC, Coates AS, Gelber RD, Thurlimann B, Senn HJ. Strategies for subtypes - dealing with the diversity of breast cancer: highlights of the St. Gallen International Expert Consensus on the Primary Therapy of Early Breast Cancer 2011. Ann Oncol. 2011;22(8):1736-1747. PMID: 21709140. doi:10.1093/annonc/ mdr304

5. Mikami Y, Ueno T, Yoshimura K, et al. Interobserver concordance of Ki67 labeling index in breast cancer: Japan Breast Cancer Research Group Ki67 ring study. Cancer Sci. 2013;104(11):1539-1543. PMID: 23905924. doi: $10.1111 /$ cas. 12245

6. Coates AS, Winer EP, Goldhirsch A, et al. Tailoring therapies-improving the management of early breast cancer: St Gallen International Expert Consensus on the Primary Therapy of Early Breast Cancer. Ann Oncol. 2015;26(8):1533-1546. PMID: 25939896. doi:10.1093/annonc/mdv221

7. Gerdes J, Schwab U, Lemke H, Stein H. Production of a mouse monoclonal antibody reactive with a human nuclear antigen associated with cell proliferation. Int J Cancer. 1983;31(1):13-20. doi:10.1002/ijc.2910310104

8. Lee LH, Yang H, Bigras G. Current breast cancer proliferative markers correlate variably based on decoupled duration of cell cycle phases. Int $J$ Cancer. 1983;31(1):13-20. doi:10.1002/ ijc. 2910310104

9. Dowsett M, Nielsen TO, A'Hern R, et al. Assessment of Ki67 in breast cancer: recommendations from the International $\mathrm{Ki}-67$ in Breast Cancer working group. J Natl Cancer Inst. 2011;103 (22):1656-1664. doi:10.1093/jnci/djr393

10. Polley MY, Leung SC, McShane LM, et al. An international Ki-67 reproducibility study. Mod Pathol. 2015;28(6):778-786. doi:10.1038/ modpathol.2015.38

11. Polley MY, Leung SC, Gao D, et al. An international study to increase concordance in Ki-67 scoring. Mod Pathol. 2015;28 (6):778-786. doi:10.1038/modpathol.2015.38

12. Gabriel NH, James LC, Carl JD, et al.; American Joint Committee on Cancer (AJCC). AJCC Cancer Staging Manual. 8th ed. New York: Springer; 2017.

13. Sparano JA, Gray RJ, Makower DF, et al. Adjuvant chemotherapy guided by a 21 -gene expression assay in breast cancer. $N$ Engl $J$ Med. 2018;379(2):111-121. doi:10.1056/NEJMoa1804710

\section{Publish your work in this journal}

Breast Cancer - Targets and Therapy is an international, peer-reviewed open access journal focusing on breast cancer research, identification of therapeutic targets and the optimal use of preventative and integrated treatment interventions to achieve improved outcomes, enhanced survival and quality of life for the cancer patient.
The manuscript management system is completely online and includes a very quick and fair peer-review system, which is all easy to use. Visit http://www.dovepress.com/testimonials.php to read real quotes from published authors. 